\section{Акулич Мария Михайловна}

доктор социологических наук, профессор кафедры общей и экономической социологии Финансово-экономического института

Тюменского государственного университета

\section{Боликова Дарья Евгеньевна}

магистрант кафедры общей и экономической социологии Финансово-экономического института Тюменского государственного университета

\section{СОТРУДНИЧЕСТВО КОНКУРИРУЮЩИХ СУБЪЕКТОВ КАК СОЦИАЛЬНАЯ СТРАТЕГИЯ}

\section{Аннотация:}

В статье представлены результаты теоретического исследования научных работ отечественных и зарубежных исследователей, посвященных изучению отношений категорий "конкуренция» и "сотрудничество». Актуальность работы высока, так как в условиях нестабильной экономиче ской ситуации для субъектов экономической деятельности и социальных практик крайне важно сохранить конкурентоспособность путем расширения форм сотрудничества, так как рыночная среда, ее трансформации, технологический прогресс и глобальные интеграционные процессы подталкивают к установлению отношений сотрудничества. Для решения этой задачи необходимо качественным образом переосмыслить традиционные социальные стратегии, базирующиеся на конку рентной борьбе, и определить перспективы при менения сотрудничества. Авторы доказывают что для российского менталитета приоритетным является сотрудничество, а не конкуренция, а также рассматривают моральные аспекты отличия данных экономико-социальных стратеаий.

Ключевые слова

сотрудничество, соконкуренция, конкуренция, конкурентные преимущества, бизнес-стратегия, социальная стратегия.
Akulich Maria Mikhaylovna

D.Phil. in Social Science, Professor, General and Economic Sociology Department, Financial and Economic Institute, Tyumen State University

Bolikova Daria Evgenyevna

Master's Degree student, General and Economic Sociology Department, Financial and Economic Institute,

Tyumen State University

\section{THE COOPERATION OF COMPETING ACTORS AS A SOCIAL STRATEGY}

The authors analyze the Russian and international studies on the relationships between the categories of competition and cooperation. The high relevance of this research is determined by the fact that the actors of economic activities and social practices have to remain intensely competitive by promoting the modalities of collaboration in the context of the unstable economic situation since the market environment, its transformations, technological advances and global integration processes lead to cooperation. To address this challenge, it is necessary to rethink the traditional social strategies which are based on competition and determine the prospects for cooperation. The authors prove that the Russian people give priority to cooperation rather than competition and consider the moral aspects of differences in these economic and social strategies.

Keywords: cooperation, co-competition, competition, competitive advantages, business strategy, social strategy.

\title{
Актуальность проблематики
}

В настоящее время формируется новый тип экономики, получивший в научной литературе название «инновационная экономика» или «экономика знаний». Данный этап характеризуется ростом значимости интеллектуального капитала, определяющего в том числе и инновационный потенциал. Иными словами, сегодня научные достижения, инновационные технологии, принципиально новые формы организации бизнеса и производства становятся едва ли не важнейшим фактором экономического роста и прогресса.

С позиций традиционного экономического подхода силой, которая вынуждает агентов постоянно искать новые виды продуктов и услуг, изобретать и совершенствовать способы их производства, является конкуренция. Однако трансформации экономической системы подразумевают, помимо всего прочего, качественные изменения отношений, возникающих между хозяйствующими субъектами, и, как следствие, структуры всей системы экономики. Наблюдается тенденция к переосмыслению стратегических подходов к выстраиванию отношений сотрудничества между субъектами экономической деятельности. На первый план выходят интеграционные процессы: инновационный потенциал человеческих ресурсов реализуется во многом благодаря совместной деятельности. Так, например, в рамках XIX Всемирного фрестиваля молодежи и студентов В.В. Путин призвал сменить соперничество на сотрудничество. Президент подчеркнул, что 
основной проблемой, мешающей установлению отношений на межгосударственном уровне, является восприятие друг друга в качестве соперников: «вместо того, чтобы сотрудничать и решать общие для всех проблемы, значительную часть ресурсов тратим, отвлекаем на вещи, которые явно являются второстепенными» [1].

Подобные процессы имеют место не только на международной политической арене, но и на уровне локальных отраслевых рынков: предприниматели, являясь, по сути, прямыми конкурентами, зачастую кооперируются для достижения поставленных стратегических целей, вступая в своеобразные альянсы.

В связи с этим представляется необходимым и актуальным переосмысление содержания и соотношения таких категорий, как «конкуренция» и «сотрудничество», представляющих собой социальные стратегии. Социальная стратегия в рамках данной работы трактуется как способ действий, реализуемых субъектом социально-экономической деятельности для достижения своих целей.

\section{Проблематика конкуренции в классической и современной научной литературе}

Конкуренцию можно определить и как «соперничество на рынке за достижение наиболее благоприятных условий существования организации и максимизации прибыли», и как «проявление социальной (потребительской) направленности процесса ведения конкурентной борьбы» [2, с. 37].

Теория конкуренции получила активное развитие преимущественно в рамках экономической науки. В связи с этим для определения специфики данной социальной стратегии целесообразно обратиться к трудам, раскрывающим феномен конкуренции с позиций как социологии, так и экономики. Также необходимо отметить наличие тесной связи между собственно экономическими теориями конкуренции и социологическими тенденциями, что обусловливает невозможность проведения четкой границы. Особенно это справедливо для такого направления исследований, как экономическая социология.

Классическая концепция конкуренции обстоятельно изложена в трудах А. Смита: экономист рассматривает развитие товарно-денежных отношений в условиях свободной конкуренции, а также описывает ее роль (удовлетворение потребностей общества, стимуляция сокращения затрат на производство, оптимизация распределения ресурсов). Другой классик экономической науки - Д. Рикардо - называет свободную конкуренцию «главным условием наращивания экономического богатства страны» [2].

К. Маркс рассматривает конкуренцию как «способ ведения промышленности», фрорму экономической борьбы предпринимателей, преследующих частные интересы и стремящихся к максимизации прибыли, за наиболее выгодные условия реализации капитала [4, с. 330].

В концепции Э. Чемберлина конкуренция предстает как динамический процесс, элемент процесса развития рыночной системы. Также Э. Чемберлин ввел в научный оборот термин «монополистическая конкуренция» - промежуточное состояние между чистой конкуренцией и монополией [5].

«Возврат к статистическому анализу» конкуренции был осуществлен в исследованиях Дж. Робинсон [6, с. 6]. Также автор ввела в научную практику разделение конкуренции на совершенную и несовершенную.

Активное развитие теории конкуренции пришлось на XX в.: данную проблематику развивали в своих трудах исследователи Й. Шумпетер, К. Макконнелл, С. Брю, Ф. Хайек и М. Портер.

Й. Шумпетер трактует конкуренцию как «соперничество старого с новым: новые товары, новые технологии, новые источники обеспечения потребностей, новые типы организации» [7, с. 158], в результате которого появляются инновации.

Представители американской школы (К. Макконнелл, С. Брю) подчеркивали значимость конкурентной борьбы между продавцами в удовлетворении потребностей покупателей. При этом авторы отмечают ряд аспектов неблагоприятного воздействия конкуренции на экономическую систему: она и создает, и разрушает равновесную цену [8].

Австрийский экономист и социолог Ф. Хайек рассматривал конкуренцию как механизм координации, распространения и освоения знания, тесно связанный с достижением человеческих благ. Подобных взглядов на сущность конкуренции придерживался американский фрилософ и социолог А. Тофффлер.

М. Портер разработал теорию конкурентных преимуществ, а также предложил методику, которая позволяет определить основы выбора конкурентных стратегий, позволяющих адаптироваться к конкурентной среде. Исследователь определил пять универсальных факторов, на основании которых описал способы формирования конкурентоспособности товаров и фирм в долгосрочной перспективе.

В России в дореволюционный период теория конкуренции фрактически не разрабатывалась. В советский период отношения соперничающих субъектов рассматривались через категорию «соревнование». Соревнование как «экономическое отношение, в противоположность конкуренции, основанием которой является обособленный труд, существует вне рынка, внутри кооперации труда» [9, с. 76]. Сущность соревнования раскрывается в работах социалистов-утопистов (В.И. Ленин, С.Р. Гершберг, Л.И. Погребной). 
Соревнование использовалось советским руководством как инструмент повышения мотивации к труду для достижения целей фрирмы или государства и подъема трудовой активности рабочих и крестьян. И хотя соревнование временно решило проблему организации масс, позволило «добиться максимальной отдачи со стороны трудящихся при минимальном удовлетворении их насущных нужд», в результате оно «не оправдало возлагавшихся на него надежд» [10, с. 267].

Понимание конкурентной борьбы как соревнования, на наш взгляд, можно определить как социальную конкуренцию - социальную стратегию, подразумевающую состязательное поведение взаимодействующих субъектов социальных процессов, которое может реализовываться в различных сферах общественной жизни. Данная трактовка соответствует общей тенденции экономико-социологического подхода к анализу феномена конкуренции, в рамках которого анализу подлежат «взаимоотношения конкурирующих агентов и тех специфических контекстов, в которые они погружены» [11, с. 55]. Данный поход представлен в работах В.В. Радаева, посвященных социологии рынков. Работы других современных российских исследователей в области конкуренции по большей части ориентированы на практическое применение теоретических изысканий западной теории конкуренции.

Сотрудничество как форма взаимодействия экономических субъектов и как социальная стратегия

Сотрудничество как механизм регулирования рынка способствует поступательному развитию производства и росту общественного благосостояния. Сотрудничество укрепляется сосуществованием рыночной общности и неравенства распределения ресурсов между участниками конкурентной борьбы. Необходимо отметить, что сотрудничество - это и социальная стратегия повышения эффективности деятельности предприятия. В этом смысле сотрудничество выступает как фактор повышения конкурентоспособности.

Важными представляются моральные аспекты различия сотрудничества и конкуренции. Конкурентная борьба регулируется деловым этикетом и нормами добросовестной конкуренции, а приемлемость тех или иных методов борьбы определяется законом. При этом нельзя поставить знак равенства между законностью и моралью: законы устанавливает государство, в то время как мораль - социокультурный конструкт, и закономерно, что кооперация более социально одобряема, чем соперничество.

Предтечей зарубежной теории сотрудничества между конкурирующими субъектами можно назвать Ф. Хайека, который определил, что экономические субъекты, находящиеся в состоянии конкуренции, существуют в общем информационном пространстве, конструируемом совместными усилиями всех его участников.

Впервые концепция сотрудничества как формы отношений между субъектами рынка была предложена О. Уильямсоном. Он называл такие формы «гибридными структурами», которые направлены на «совместное создание дополнительных ценностей», распределяемых между «сотрудничающими участниками взаимовыгодным способом» [12, с. 127]. Аналогичный подход развивается Л. Мизесом, Ф. Найтом, И. Кирцнером, П. Друкером, акцентирующими внимание на информационной природе конкурентного процесса, участники которого действуют в условиях неопределенности [13, с. 6].

Теория сотрудничества между конкурентами изложена в рамках концепции соконкуренции (coopetition) А. Бранденбургера и Б. Нейлбаффра. Авторы полагают, что конкуренция перестает отвечать сущности современных экономических отношений, а наиболее выгодная стратегия сочетание конкуренции и сотрудничества. В условиях соконкуренции отношения между глобальными конкурентами определяются взаимозависимостью с кооперацией и конкуренцией как двумя самостоятельными, но взаимосвязанными процессами.

Я. Ло отмечает, что соконкуренция подразумевает сосуществование конкуренции и сотрудничества со всеми конкурентами, а не сотрудничество с одними и конкурентную борьбу с другими [14, р. 130]. Также автор определяет ряд фракторов роста значимости отношений сотрудничества и конкуренции [14, р. 132-133]: осознание заключившими соглашение о сотрудничестве участниками рынка угрозы со стороны других коопераций; необходимость реагировать на изменение потребительских запросов, которые становятся все более изощренными; возрастающее давление цепочки добавленной стоимости и институциональных структур при росте значимости конкуренции, при растущем сходстве и/или пересечении интересов конкурирующих субъектов; стабилизация конкуренции в отрасли, сокращение объема ресурсов.

На наш взгляд, термин «соконкуренция» недостаточно полно описывает потенциал интеграций экономических субъектов, поэтому целесообразно использовать термин «сотрудничество».

Социология рассматривает сотрудничество как фрорму социального взаимодействия (социальных отношений), противопоставляя конкуренции и конфликту. Поэтому в контексте теоретического анализа теорий сотрудничества применительно к конкурирующим субъектам целесообразно упомянуть социологические теории взаимодействия. С позиций теории социального об- 
мена Дж. Хоманса, взаимодействие рассматривается как процесс обмена материальными и нематериальными ценностями. Символический интеракционизм рассматривает кооперацию и ассоциацию, основывающуюся на толковании действий.

Исходя из вышеописанных положений, можно сформулировать следующее определение сотрудничества как социальной стратегии: сотрудничество - это направленность субъекта социально-экономической деятельности на достижение поставленных целей путем взаимовыгодного обмена ресурсами, партнерства и кооперации с другими участниками социальных процессов.

В настоящее время наиболее приоритетными областями реализации стратегии сотрудничества (в особенности для России) являются экономическая и политическая сферы.

\section{Обзор эмпирических исследований феномена сотрудничества}

Практические исследования в этой области можно различать по уровню анализа. Значительная доля работ приходится на межфирменный или организационный уровень. Предметной областью исследования при этом является феномен сотрудничества между двумя конкурирующими фирмами или организациями. Так, М. Бенгтссон и С. Кок [16] оперируют результатами исследования двух шведских и одной финской отраслей промышленности. Ключевой задачей стала разработка рекомендаций по разделению и управлению отношениями конкуренции и сотрудничества. Результаты исследования показывают, что данные отношения делятся в зависимости от степени доступа конкурентов к ресурсам и близости к клиенту (покупателю). К. КинтанаГарсия и К. Бенавидес-Веласко [17] анализируют влияние сопутствующей стратегии на технологическое разнообразие и разработку новых продуктов на базе выборки европейских специализированных биотехнологических фирм.

С. Энберг [18] предпринимает попытку выявить динамические аспекты коопераций на межиндивидуальном уровне. Автор рассматривает возможность интеграции знаний в кооперативные проекты в области НИОКР. Согласно результатам данного исследования, интеграция знаний в кооперативном проекте НИОКР не строится на основе общих знаний или совместного понимания содержания проектной работы, но обеспечивается общим пониманием процесса работы над проектом.

Подобные исследования проводились на внутриорганизационном и сетевом уровнях. Например, В. Цай [19] исследует эффрективность механизмов координации обмена знаниями в рамках внутриорганизационных сетей, которые состоят как из совместных, так и из конкурентных связей между организационными подразделениями. Для анализа характера влияния формальной иерархической структуры и неформальных отношений на обмен знаниями автор использует социометрические методы. Результаты показывают, что формальная иерархическая структура в форме централизации оказывает существенное негативное влияние на обмен знаниями, а неформальные боковые отношения в форме социального взаимодействия оказывают значительное положительное влияние на обмен знаниями между бизнес-единицами, которые конкурируют с друг с другом за доли рынка, но не среди акторов, которые конкурируют друг с другом за внутренние ресурсы.

Анализ феномена сотрудничества конкурентов широко применим к различным отраслям: нефтехимические продукты (В. Цай [20]), розничная торговля (Г. Коцаб, К. Теллер [21]), транспорт (П. Гвинн), финансы (В. Чакон [22]), туризм (Ю. Ван, С. Краковер), образование (А. Нэйр [23]) и др.

Российские исследователи также занимаются изучением феномена соконкуренции. А.А. Лубнина, С.Ш. Останина, М.М. Шарафутдинова, И.В. Лущик описывают практические результаты исследования фрорм сотрудничества предприятий промышленного сектора [24]. Авторы провели анализ эфффективности инновационно активных предприятий за 2010-2015 гг., который охватил 100 предприятий, репрезентативно представляющих производственный сектор Республики Татарстан. По результатам исследования были выделены несколько секторов, в которых использование стратегии соконкуренции представляется наиболее оптимальным.

\section{Заключение}

Проведенный анализ показал, что традиционно конкуренцию принято трактовать как форму экономического взаимодействия, проявляющуюся в борьбе за ресурсы и «уничтожении» соперников. Однако в современных социально-экономических условиях акцентирование внимания на состязательном аспекте представляется нерациональным. Социально-экономические субъекты не только преследуют собственные, частные цели, но и имеют общие интересы. В связи с этим оптимальным видится применение противоположной социальной стратегии - сотрудничества. При этом под сотрудничеством следует понимать направленность субъекта социально-экономической деятельности на достижение поставленных целей путем взаимовыгодного обмена ресурсами, партнерства и кооперации с другими участниками социальных процессов.

Расширение сотрудничества (в частности, между конкурирующими субъектами) способно создать дополнительный импульс развития всей экономической системы и способствовать предпринимательскому росту, что особенно важно в текущих экономических условиях. 
Сама рыночная среда, ее трансформации, технологический прогресс и глобальные интеграционные процессы подталкивают экономических субъектов к установлению отношений сотрудничества. Это особенно актуально для местного бизнеса, малых и средних предпринимателей в условиях борьбы с импортными товарами и услугами и игроками, пришедшими на рынок извне.

Межорганизационное сотрудничество становится важной частью корпоративной стратегии, позволяющей справляться с более быстрой динамикой бизнеса и большей неопределенностью, например нестабильностью экономики и бизнес-среды, агрессивной экономической конкуренцией и интенсивным распространением инноваций среди фирм.

Несмотря на очевидную выгоду установления отношений сотрудничества и их объективную необходимость, многие субъекты экономической деятельности сохраняют скептицизм по отношению к стратегическим планам развития, предполагающим сотрудничество с конкурентами. В связи с этим важно направить усилия на формирование на всех уровнях культуры сотрудничества, которая будет оптимизировать и адаптировать экономические, социальные, политические, духовные отношения между участниками к происходящей ситуации.

\section{Ссылки:}

1. Путин призвал страны отказаться от соперничества и перейти к партнерству [Электронный ресурс] // XIX Bсемирный фестиваль молодежи и студентов. 2017. 15 окт. URL: http://tass.ru/wfys2017/articles/4647699 (дата обращения: 14.01.2018).

2. Ермолов М.Г., Набиев Р.А. Теоретические аспекты понятия «конкуренция» // Вестник Удмуртского университета. Серия «Экономика и право». 2014. № 4. С. 37-41.

3. Цит. по: Ермолов М.Г., Набиев Р.А. Указ. соч. С. 37.

4. Маркс К., Энгельс Ф. Сочинения : в 50 т. 2-е изд. Т. 4. Принципы коммунизма. М., 1955. 615 с.

5. Цит. по: Бархатов В.И. Теоретико-методологические аспекты совершенной и несовершенной конкуренции // Вестник Челябинского государственного университета. 2008. № 1. С. 5-17.

6. Там же. С. 6.

7. Шумпетер Й.А. Теория экономического развития. М., 1982. $401 \mathrm{c.}$

8. Bengtsson M., Kock S. "Coopetition" in Business Networks - To Cooperate and Compete Simultaneously // Industrial Marketing Management. 2000. Vol. 29, no. 5. P. 411-426.

9. Петрищев М.В. Конкуренция и соревнование: сравнительный анализ // Проблемы современной экономики. 2011. № 4. С. 76-79.

10. Сверлик Г.И. Соревнование, не оправдавшее надежд // Crede Experto: транспорт, общество, образование, язык. 2014. № 3 (12). С. 256-268.

11. Радаев В.В. Социология рынков: к формированию нового направления. М., 2003. 328 с

12. Цит. по: Терешин А.В. Интеграция партнерства и конкуренции в предпринимательстве // ЭТАП: экономическая теория, анализ, практика. 2015. № 5. С. 127-136.

13. Ведин Н.В. Диалектика сотрудничества и конкуренции в хозяйственной эволюции общества : автореф. дис. ... д-ра экон. наук. Казань, 2007. 44 с.

14. Luo Y. A Coopetition Perspective of Global Competition // Journal of World Business. 2007. Vol. 42, no. 2. P. $129-144$. https://doi.org/10.1016/j.jwb.2006.08.007.

15. Ibid. P. 132-133.

16. Bengtsson M., Kock S. Op. cit.

17. Quintana-Garcia C., Benavides-Velasco C. Cooperation, Competition, and Innovative Capability: A Panel Data of European Dedicated Biotechnology Firms // Technovation. 2004. Vol. 24, no. 12. P. 927-938. https://doi.org/10.1016/S01664972(03)00060-9.

18. Enberg C. Enabling Knowledge Integration in Coopetitive R\&D projects: The Management of Conflicting Logics // International Journal of Project Management. 2012. Vol. 30, no. 7. P. 771-780.

19. Tsai W. Social Structure of "Coopetition" within a Multiunit Organization: Coordination, Competition, and Intraorganizational Knowledge Sharing // Organization Science. 2002. Vol. 13, no. 2. P. 179-190.

20. Ibid.

21. Kotzab H., Teller C. Value-adding Partnerships and Co-opetition Models in the Grocery Industry // International Journal of Physical Distribution \& Logistics Management. 2003. Vol. 33, no. 3. P. 268-281. https://doi.org/10.1108/09600030310472005.

22. Czakon W. Power Asymmetries, Flexibility and the Propensity to Coopete: An Empirical Investigation of SMEs' Relationships with Franchisors // International Journal of Entrepreneurship and Small Business. 2009. Vol. 8, no. 1. P. 44-60. https://doi.org/10.1504/IJESB.2009.024104.

23. Nair A., Narasimhan R., Bendoly E. Coopetitive Buyer-supplier Relationship: An Investigation of Bargaining Power, Relational Context, and Investment Strategies // Decision Science. 2011. Vol. 42, no. 1. P. 93-127. https://doi.org/10.1111/j.15405915.2010.00303.x.

24. Специфика потенциала инновационных форм сотрудничества промышленных предприятий / А.А. Лубнина, С.Ш. Останина, М.М. Шарафутдинова, И.В. Лущик // Бизнес. Образование. Право. Вестник Волгоградского института бизнеса. 2017. № 1 (38). С. 51-55.

\section{References:}

Barkhatov, VI 2008, 'Theoretical and methodological aspects of perfect and imperfect competition', Vestnik Chelyabinskogo gosudarstvennogo universiteta, no. 1, pp. 5-17, (in Russian).

Bengtsson, M \& Kock, S 2000, '“Coopetition" in Business Networks - To Cooperate and Compete Simultaneously', Industrial Marketing Management, vol. 29, no. 5, pp. 411-426. https://doi.org/10.1016/s0019-8501(99)00067-x. 
Czakon, W 2009, 'Power Asymmetries, Flexibility and the Propensity to Coopete: An Empirical Investigation of SMEs' Relationships with Franchisors', International Journal of Entrepreneurship and Small Business, vol. 8, no. 1, pp. 44-60. https://doi.org/10.1504/IJESB.2009.024104.

Enberg, C 2012, 'Enabling Knowledge Integration in Cooperative R \& D projects: The Management of Conflicting Logics', International Journal of Project Management, vol. 30, no. 7, pp. 771-780. https://doi.org/10.1016/j.jproman.2012.01.003.

Ermolov, MG \& Nabiev, RA 2014, 'Theoretical aspects of the concept of competition', Vestnik Udmurtskogo universiteta. Seriya "Ekonomika i pravo", no. 4, pp. 37-41, (in Russian).

Kotzab, H \& Teller, C 2003, 'Value-adding Partnerships and Co-opetition Models in the Grocery Industry', International Journal of Physical Distribution \& Logistics Management, vol. 33, no. 3, pp. 268-281. https://doi.org/10.1108/09600030310472005.

Lubnina, AA, Ostanina, SSh, Sharafutdinova, MM \& Lushchik, IV 2017, 'Specific nature of the capacity of innovative forms of industrial enterprises cooperation', Biznes. Obrazovaniye. Pravo. Vestnik Volgogradskogo instituta biznesa, no. 1 (38), pp. 5155, (in Russian).

Luo, Y 2007, 'A Cooperative Perspective of Global Competition', Journal of World Business, vol. 42, no. 2, pp. 129-144. https://doi.org/10.1016/j.jwb.2006.08.007.

Marx, K \& Engels, F 1955, The collected works, in 50 vols., 2nd ed., vol. 4, Moscow, 615 p., (in Russian).

Nair, A, Narasimhan, R \& Bendoly, E 2011, 'Cooperative Buyer-supplier Relationship: An Investigation of Bargaining Power, Relational Context, and Investment Strategies', Decision Science, vol. 42, no. 1, pp. 93-127. https://doi.org/10.1111/j.15405915.2010.00303.x.

Petrischev, MV 2011, 'Rivalry and competition: a comparative analysis', Problemy sovremennoy ekonomiki, no. 4, pp. 7679, (in Russian).

'Putin urged countries to abandon rivalry and turn to partnership' 2017, XIX Vsemirnyy festival' molodezhi i studentov, 15 October, viewed 14 January 2018, <http://tass.ru/wfys2017/articles/4647699>, (in Russian).

Quintana-Garcia, C \& Benavides-Velasco, C 2004, 'Cooperation, Competition, and Innovative Capability: A Panel Data of European Dedicated Biotechnology Firms', Technovation, vol. 24, no. 12, pp. 927-938. https://doi.org/10.1016/S01664972(03)00060-9.

Radaev, VV 2003, Sociology of markets: concerning the new trend development, Moscow, 328 p., (in Russian).

Schumpeter, JA 1982, The theory of economic development, Moscow, 401 p., (in Russian).

Sverlik, Gl 2014, 'Disappointing competition', Crede Experto: transport, obshchestvo, obrazovaniye, yazyk, no. 3 (12), pp. 256-268, (in Russian).

Tereshin, AV 2015, 'Integration of partnership and competition in entrepreneurship', ETAP: ekonomicheskaya teoriya, analiz, praktika, No. 5, pp. 127-136, (in Russian).

Tsai, W 2002, 'Social Structure of "Coopetition" within a Multiunit Organization: Coordination, Competition, and Intraorganizational Knowledge Sharing', Organization Science, vol. 13, no. 2, pp. 179-190. https://doi.org/10.1287/orsc.13.2.179.536.

Vedin, NV 2007, Dialectics of cooperation and competition in the economic evolution of society, D. Phil. thesis abstract, Kazan, 44 p., (in Russian). 